\title{
Effect of different surface treatments on bond strength between zirconia posts and root surfaces
}

\author{
Berivan Dündar Yılmaz' ${ }^{\oplus}$, Ayça Deniz İzgi2 $₫$ \\ ${ }^{1}$ Dicle University, Faculty of Dentistry, Department of Prosthodontics, Diyarbakır, Turkey
}

\section{Correspondence:}

Dr. Berivan DÜNDAR YILMAZ Dicle University, Faculty of Dentistry, Department of Prosthodontics, Diyarbakır, Turkey.

E-mail:

berivandndr@yahoo.com

Received: 25 October 2019 Accepted: 02 August 2020

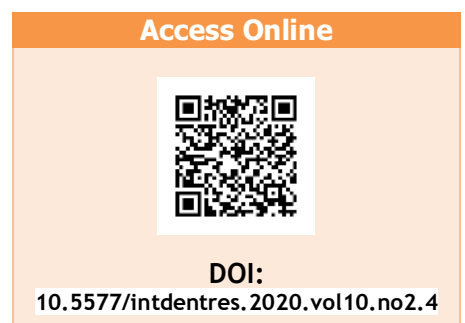

10.5577/intdentres.2020.vol10.no2.4

\section{Abstract}

Aim: In recent years, especially with the increase in aesthetic demands, there has been a requirement to use the best aesthetic materials for dental restorations. These restorations are especially needed in those teeth that have crown loss due to a tooth fracture or extreme anterior tooth decay, post-core treatment has been applied as getting support by tooth roots. Current treatments involve removing the aesthetic disadvantages and making use of the strength resistance of various metals. In this case, zirconium, which is a white-coloured metal, is preferred. In this study, zirconia posts with different surface treatments were cemented to the root canal and bond strength was then evaluated.

Methodology: Forty mandibular second premolar teeth were used in this study. Crowns of all teeth were removed to $14 \mathrm{~mm}$ from the enamel-cement margin by separation under irrigation. Root canals were cleaned, shaped and filled. Teeth were kept in distilled water while zirconia posts were prepared. Zirconia posts were divided into four groups according to the surface treatment methods as follows: a control group, a CoJet applied group, a sandblasting+laser group and an Er:YAG laser group. The Er:YAG laser was administered at $450 \mathrm{~mJ}$ at $10 \mathrm{~Hz}$ for 60 seconds with a $100-\mu s$ pulse duration. Surface-treated posts were bonded to the root canal with Panavia $\mathrm{F}$ cement. Cores were made with the standardized strip crowns. 5000 cycles, $5-55{ }^{\circ} \mathrm{C}$ thermal cycle applied with transition time at 5 seconds. For push-out tests, roots were embedded in translucent acrylic resin and coronal, middle third and apical sections were cut into $1.5-\mathrm{mm}$ slices. The maximum load at failure was recorded for each specimen in newtons and then converted into megapascals (MPa). Each specimen was inspected with a scanning electron microscope (SEM) at a magnification of 100 $X$. Data were analysed using Games-Howell tests with a significance level of 0.05 . Results: The coronal section from Group 3 had the highest mean push-out bond strength $(18.01 \mathrm{MPa})$, while the apical section from Group 1 had the lowest (4.49 $\mathrm{MPa}$ ). Surface treatments had no significant effect on the mean push-out bond strengths of zirconia posts $(p>0.05)$. However, dividing the root canal into three sections had a significant effect on bond strength $(p<0.05)$. When the results were evaluated for all groups, the push-out bond strength was highest in the coronal section, then in the middle third and the lowest in the apical section.

Conclusion: The combined application (sandblasting+laser) had a significant effect on the push-out bond strength of zirconia posts. The root region also had a significant effect on bond strength and there was a significant difference between the apical and coronal sections.

Keywords: Bond strength, zirconia posts, Er:yag laser, push-out test, SEM

How to cite this article: Dündar Yılmaz B, İzgi AD. Effect of different surface treatments on bond strength between zirconia posts and root surfaces. Int Dent Res 2020;10(2):49-54. https://doi.org/10.5577/intdentres.2020.vol10.no2.4 


\section{Introduction}

The rapid increase in aesthetic requirements in recent years requires the use of aesthetically superior materials in dental restorations. Therefore, aesthetic posts combined with all-ceramic crowns, such as zirconia-based ceramics, especially in broken or coloured endodontically treated anterior teeth, have become preferred for aesthetic purposes $(1,2)$. Despite the stabilization of the tetragonal phase, transformation of its tetragonal state to the monoclinic phase continuously occurs (3). This transformation toughening property is responsible for its high fracture resistance (4). Therefore, further studies are needed to increase the retention of zirconia posts to the root canal (5). Clinical success is related to mechanical integrity and the bond strength of the materials. For this reason, new strategies are needed to increase the surface roughness of zirconia. One of these strategies is to increase the bond strength at the interface (4). Different surface treatments, such as sandblasting with aluminium oxide particles, etching with acid, silane application, silica coating or a combination of these treatments, applied to the post surface have been used to increase the bond strength (5).

Sandblasting with alumina particles results in increased roughness of the surface and micro-retentive areas $(6,7)$. The purpose of acid etching is to remove the smear layer left by the high-speed dental drill and to create an irregular surface by preferentially dissolving hydroxyapatite crystals on the outer surface. This topography facilitates the penetration of the fluid adhesive components into the irregularities (8). Primers, such as silane, contain functional monomers that create chemical adhesion and silica materials, which are chemically composed of silica with nanometric pores $(5,6)$.

Recently, there has also been growing interest and progress in the use of lasers in the dental field $(7,8)$. Lasers cause surface roughening and irregularities, similar to the surface following acid etching. Furthermore, laser etching of the surface has been reported to yield an anfractuous surface and open dentin tubules, both ideal for adhesion (8).

In this study, we aimed to investigate the application of laser treatment and a combination of laser and sandblasting as alternatives to different surface treatments that increase bonding resistance and then determine how they affect surface roughness.

\section{Materials and Methods}

Forty mandibular second premolar teeth, which were extracted for periodontal or orthodontic treatment, were used for this study. The teeth were non-carious and had no previous restorations. Crowns of all teeth were removed to $14 \mathrm{~mm}$ from the enamelcement margin by separation under irrigation with a diamond disk (M Diatek). Root canal preparations were performed using Gates Glidden drills (Dentsply) and irrigated with $5 \% \mathrm{NaOCl}$ and filled with gutta-percha (Dentsply). After root canal treatments, teeth were kept in distilled water while zirconia posts were prepared. The fabricated ParaPost was used as a zirconia post.

The specimens were randomly divided into four groups of 10 teeth each, as follows:

Group 1: No surface treatment.

Group 2: CoJet (CoJet Sand Blast Coating Agent, $3 M$ ESPE) system with $30-\mu \mathrm{m}$ silica-coated alumina particles with 0.28 megapascals $(\mathrm{MPa})$ of pressure.

Group 3: Sandblasting with $110-\mu \mathrm{m}$ aluminium oxide particles with $0.15 \mathrm{MPa}$ of pressure plus Er:YAG laser irradiation at $450 \mathrm{~mJ}, 10 \mathrm{~Hz}$ and $4.5 \mathrm{~W}$ for 60 seconds with a 100-us pulse duration.

Group 4: Er:YAG laser irradiation treatment at 450 $\mathrm{mJ}, 10 \mathrm{~Hz}$ and $4.5 \mathrm{~W}$ for 60 seconds with a $100-\mu$ s pulse duration.

After determining groups with different surface treatments, posts were cemented to the root canal with Panavia F 2.0 (Kuraray Dental) cement. These procedures were made according to the manufacturer's suggestions. Cores were made with the standardized strip crowns (Clearfil Photo Core, Kuraray Dental, USA/Canada).

The specimens were then embedded in autopolymerising acrylic resin (Orthocryl EQ; Dentaurum, Ispringen, Germany) using a $2.5 \times 2.5 \times 2 \mathrm{~cm}$ standard acrylic matrix with coronal, middle third and apical sectioning into $1.5-\mathrm{mm}$ slices. Push-out tests were performed with the zirconia post and the root canal surface on the crosshead of the universal testing machine (Instron Corp., Canton, USA) at a speed of $2 \mathrm{~mm} / \mathrm{min}$. The maximum load at failure was recorded for each specimen in newtons and then converted into $\mathrm{MPa}$.

\section{Scanning Electron Microscope Analysis}

Following push-out testing, all samples were sent to the KOSGEP research laboratory at Erciyes University, Turkey. The scanning electron microscope (SEM) images of the tooth surfaces were obtained at a magnification of $100 \times$ (Leo 440 computer-controlled digital SEM).

\section{Statistical Analysis}

Statistical analyses were performed with IBM SPSS V23 (SPSS Inc, Chicago, IL, USA) and carried out using Games-Howell and Tukey post-hoc tests. Group comparisons were made using one-way analysis of variance (ANOVA) with 95\% confidence. Post-hoc tests with Games-Howell statistics were applied. $p$ values< 0.05 were considered statistically significant. 


\section{Results}

Bond strengths between surface-treated zirconia posts and root canal surfaces sectioned into coronal, middle third and apical sections for each group subjected to push-out testing are given in Graphic 1. The means and standard deviations of the four groups are shown in Table 1. According to the statistical results, Group 1 (control), Group 2 (CoJet) and Group 3 (sandblasted+laser) showed no significant differences $(p>0.05)$ between each other, but all of these groups showed a significant difference $(p<0.05)$ compared with Group 4 (laser).

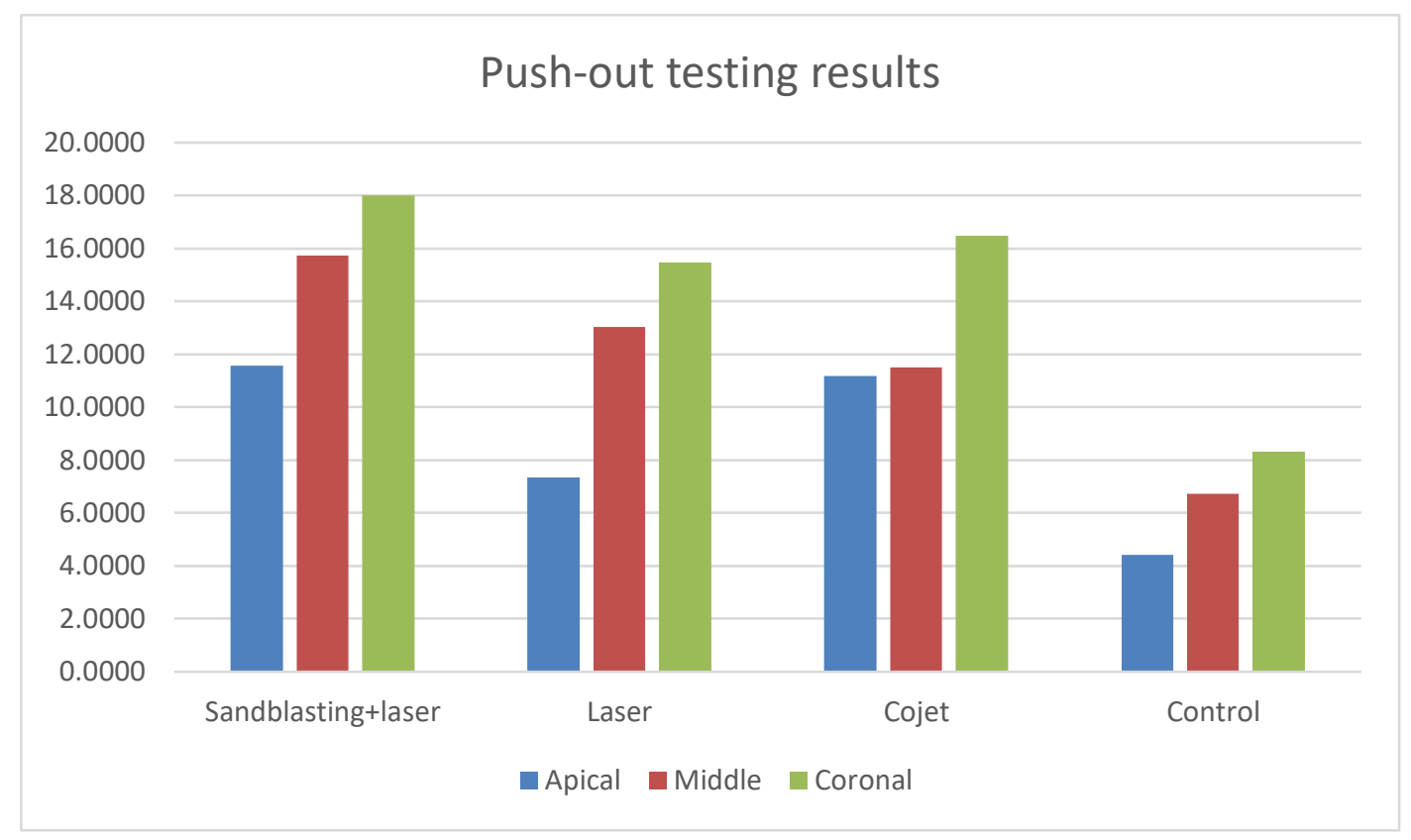

Graphic 1. The bond strengths between the surface treated zirconia posts and the root canal surface

sectioned into coronal,middle triple and apical in each group subjected to push-out testing.

Surface treatments had no significant effect on the mean push-out bond strengths of zirconia posts ( $p$ $>$ 0.05). The Group 3 (sandblasted+laser) coronal section had the highest mean push-out bond strength $(18.01 \pm 4.58 \mathrm{MPa})$, while the Group 1 (control) apical section had the lowest $(4.49 \pm 4.51 \mathrm{MPa})$. The push-out bond strength values of the four groups were in the following order: Group $1<$ Group $4<$ Group $2<$ Group 3.

Dividing the root canal into three sections had a significant difference on bond strength $(p<0.05)$. According to the statistical analyses, there was a significant difference between the apical and coronal sections $(p=0.00)$; however, there were no significant differences between the apical and middle third sections or the coronal and middle third sections $(p>$ 0.05) of the root canal. The means and standard deviations of the groups are shown in Table 2. When the results were evaluated for all groups, the push-out bond strength was highest in the coronal section, then in the middle third section and lowest in the apical section.

Bond failure at the zirconia post/luting agent interface was recorded in $62.5 \%$ of all groups (control, CoJet, sandblasted+laser, laser). Mixed failures were recorded in $75 \%$ of all groups. When groups were evaluated, bond failure was found mostly in the control group (Group 1) and laser group (Group 4), while the sandblasting+laser group (Group 3) was the least in support of bond strength results. When the divided sections were evaluated in SEM images, more bond failure was observed in apical sections than in coronal sections, which supported the statistical findings. Different failure modes of groups observed in the SEM images are presented in Figure 1. 


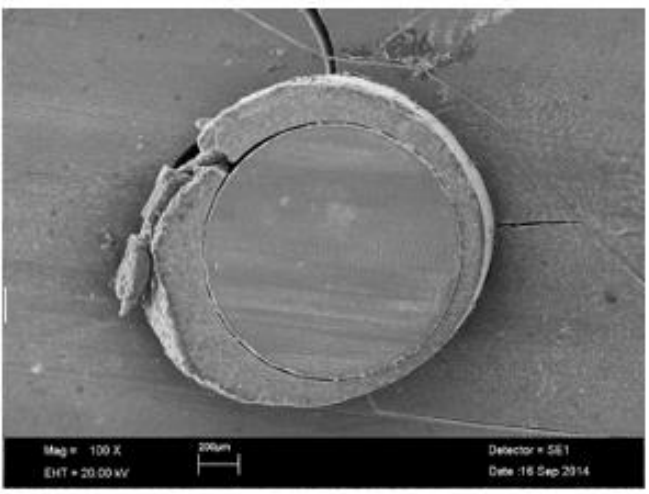

Group 1: Adhesive + Cohesive (luting-post, luting-dentin)

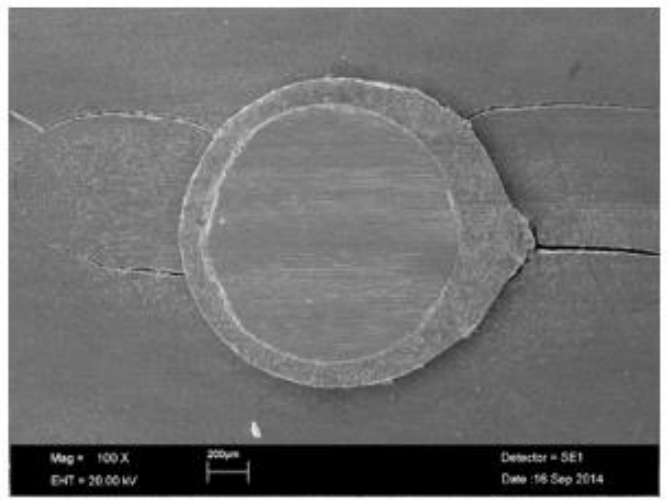

Group 3: Adhesive + Cohesive (luting-post, luting-dentin)

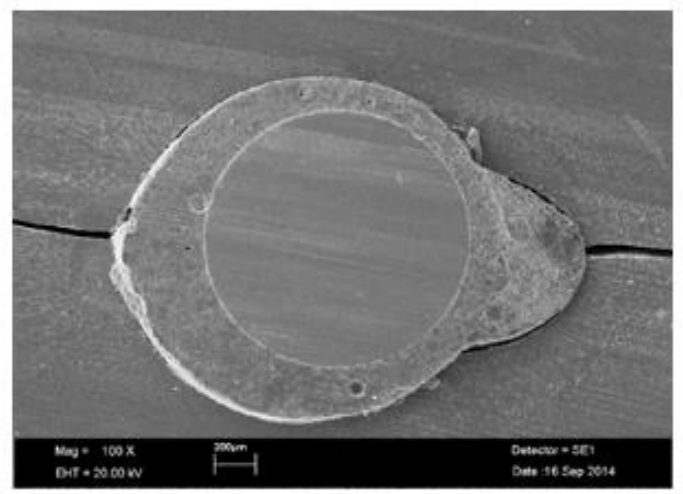

Group 2: Adhesive (luting-dentin)

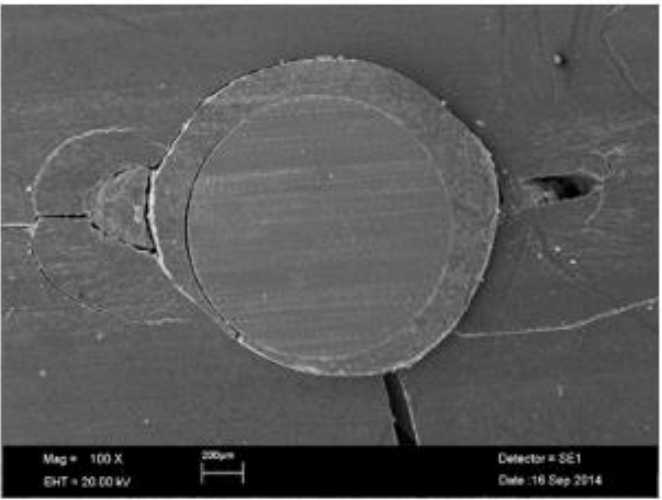

Group 4: Adhesive (luting-dentin)

Figure 1. Different failure modes of groups observed in the SEM images.

Table 1. The means and standard deviations of the four groups.

\begin{tabular}{lcccc} 
Groups & Comparison & Mean Difference & Standart Deviation & $p$ \\
\hline Group 1 & Group 2 & $-6,53845$ & 1,39293 & 0,000 \\
& Group 3 & $-8,59105$ & 1,29613 & 0,000 \\
Group 4 & $-4,44432$ & 1,48285 & 0,003 \\
Group 2 & Group 1 & 6,53845 & 1,39293 & 0,000 \\
& Group 3 & $-2,05260$ & 1,58343 & 0,569 \\
& Group 4 & 1,09413 & 1,73958 & 0,922 \\
Group 3 & Group 1 & 8,59105 & 1,29613 & 0,000 \\
& Group 2 & 2,05260 & 1,58343 & 0,569 \\
& Group 4 & 3,14672 & 1,66308 & 0,243 \\
\hline Group 4 & Group 1 & 5,44432 & 1,48285 & 0,003 \\
& Group 2 & $-1,09413$ & 1,73958 & 0,922 \\
& Group 3 & $-3,14672$ & 1,66308 & 0,243 \\
\hline
\end{tabular}


Table 2. The means and standard deviations of root canals divided into 3 sections.

\begin{tabular}{|c|c|c|c|c|}
\hline Groups & Comparison & Mean Difference & Standart Deviation & $p$ \\
\hline Group 1 & Group 2 & $-3,30859$ & 1,39750 & 0,053 \\
\hline (Apical sec.) & Group 3 & $-5,89931$ & 1,34673 & 0,000 \\
\hline \multirow{2}{*}{\multicolumn{5}{|c|}{ Group 2 (Middle sec.) }} \\
\hline & & & & \\
\hline & Group 3 & $-2,59072$ & 1,41113 & 0,165 \\
\hline Group 3 & Group 1 & $-5,89931$ & 1,34673 & 0,000 \\
\hline (Coronal sec.) & Group 2 & $-2,59072$ & 1,41113 & 0,165 \\
\hline
\end{tabular}

\section{Discussion}

The higher elasticity of metal posts than dentine, the formation of fractures, not being used with light-curing cement and the fact that they become corroded under aesthetic restorations over time, have led researchers to different post-core systems $(9,10)$. With the development of non-metal posts, biocompatibility, high fracture resistance and aesthetic expectations, such as meeting the characteristics of ceramic materials applied as a post-core, have shown successful results $(11,12)$. Compared to other ceramic materials, zirconium oxides are used in dentistry because of their superior properties (13). In our study, zirconia, which is both aesthetic and durable, was used.

Christel et al. examined the zirconia posts introduced in the late 1980s and reported that these posts have a high resistance to fracture (14). Moreover, Kwiatkowski and Geller found that zirconia posts have high bonding capacities to silane and resin cement (15).

Resin cements tightly adhere to the restoration surface and the micromechanical integrity and activation of the restoration surface depends on the chemical bonding that can be achieved $(12,16)$. To increase the bond strength at the interface, various surface treatments have been used. Among these surface treatments, include mechanical, chemical and combinations of mechanical and chemical bonding $(5,6)$.

It has been reported that untreated zirconia posts have a relatively smooth surface that limits mechanical bonding between the post surface and resin cements (17-19). Sahafi et al. reported that sandblasting with Al2O3 particles and a CoJet system on post surfaces is an effective method for increasing the bond strength between adhesive resins and posts (20). In our study, surface sandblasting treatment with 110- $\mu \mathrm{m} \mathrm{Al2O3}$ particles was used to enhance mechanical bonding, and tribochemical silica coating (CoJet) was applied to form a combination of mechanical and chemical bonding.

Some researchers have reported that laser treatment provides greater surface roughness than standard methods (8). Lasers have been suggested to modify the surface by relatively safe and easy means (7). Kern et al. compared a silane application, a tribochemical silica coating and sandblasting with $\mathrm{Al} 2 \mathrm{O} 3$ and found that sandblasting with $\mathrm{Al} 2 \mathrm{O} 3$ is a more successful method of surface treatment (21). Akin et al. irradiated a zirconia surface with an Er:YAG laser and reported that laser irradiation increases the surface roughness and surface irregularities compared to untreated specimens (7). Sandblasting with Al2O3 alone on the zirconia post surface is reported to be ineffective on the level of bond strength $(22,23)$. Almuhlef et al. reported that both the surface treatment and the root region have no significant effects on the push-out bond strength of zirconia posts (24).

On the basis of these results, we compared surface treatment methods by adding a sandblasting+laser application method to conventional surface treatments and found the highest bond strength (18.01 MPa) in this group. We also found that the root region had a significant effect on bond strength $(p<0.05)$. Furthermore, there was a significant difference between apical and coronal sections $(p=0.00)$.

\section{Conclusions}

Based on the results of this study, our conclusions are indicated below.

1. The combined application (sandblasting+laser) had a significant effect on the push-out bond strength of zirconia posts.

2. The root region had a significant effect on bond strength. 
3. According to multiple comparisons of sections (coronal, middle third and apical), the apicalcoronal section was significantly different, while the apical-middle third and coronalmiddle third had no significant differences.

Ethical Approval: Ethics committee approval was received for this study from Dicle University, Ethics Committee in accordance the World Medical Association Declaration of Helsinki, with the approval number: 2019/59.

Peer-review: Externally peer-reviewed.

Author Contributions: Conception - B.D.Y., A.D.í Design - B.D.Y., A.D.i; Supervision - A.D.i; Materials - B.D.Y., A.D.i; Data Collection and/or Processing - B.D.Y.; Analysis and/or Interpretation - B.D.Y.; Literature Review - B.D.Y., A.D.I; Writer - B.D.Y.; Critical Review A.D.i.

Conflict of Interest: No conflict of interest was declared by the authors.

Financial Disclosure: The authors declared that this study has received no financial support.

\section{References}

1. Kıvanç BH. Endodontik tedavili dișlerde post uygulamaları. Atatürk Ünv. Diș Hek. Fak. Derg 2006; 2(4):18-23.

2. Koutayas SO, Kern M. All-ceramic posts and cores: The state of the art. Quintessence Int 1999;30:383-392.

3. Vigolo $P$, Givani A. Clinical evaluation of single-tooth mini implant restorations: a five-year retrospective study. Journal of Prosthetic Dentistry 2000;84(1):50-4. (Crossref)

4. Martins FV, Mattos CT, Cordeiro WJB and Fonseca EM. Evaluation of zirconia surface roughness after aluminium oxide airborne-particle abrasion and the erbium-YAG, neodymiumdoped YAG, or $\mathrm{CO} 2$ lasers: A systematic review and metaanalysis. Journal of Prosthetic Dentistry 2019;121(6):895-903. (Crossref)

5. Feng X, Sun T, Liu R, Zhang Y. Influence of mesoporous silica coating treatment on push-out bond strength of zirconia posts. Bio-medical materials 2014;24(6):2187-2195. (Crossref)

6. Bedran-de-Castro AKB, Ambrosano GMB. Thermal and Mechanical Load Cycling on Microleakage and Shear Bond Strength to Dentin. Operative Dentistry 2004;29(1): 42-48.

7. Arslan H, Kurklu D, Ayrancı LB et al. Effects of post surface treatments including Er:YAG laser with different parameters on the pull-out bond strength of the fiber posts. Lasers in Medical Science 2014;29(5):1569-1574. (Crossref)

8. Dündar B, Güzel KG. An analysis of the shear strength of the bond between enamel and porcelain laminate veneers with different etching systems: acid and Er,Cr:YSGG laser separately and combined. Lasers in Medical Science 2011;26(6):777-782. (Crossref)

9. Korn SB, von Fraunhofer JA, Mueninghoff LA. An in vitro comparasion of two dowel and core techniques for endodontically treated molars. J Prosthet Dent 1984;51:509. 514. (Crossref)

10. Eskitaşçıoğlu G, Belli S, Kalkan M. Evaluation of two post core systems using two different methods. J Endodont 2002;28:629633. (Crossref)

11. Butz F, Lenon AM, Heydecke $G$ et al. Survival rate and fracture strength of endodontically treated teeth maxillary incisors with moderate defects restored with different post-and-core systems: an in vitro study. Int J Prosthodont 2001;14(1):58-64.

12. Özkurt Z, Isseri U, Kazazoğlu E. Zirconia ceramic post systems: a literature review and a case report. Dent Mater J 2010;29(3):233-245. (Crossref)

13. Uludamar A, Akalın B, Özkan YK. Zirkonyum esaslı tam seramik restorasyonlarda simantasyon öncesi yüzey hazırlıkları. Cumhuriyet Dent J 2011;14(2):140-153.

14. Christel $P$, Meunier $A$, Heler $M$ et al. Mechanical properties and short-term in-vivo evaluation of ytrium-oxide-partiallystabilizied zirconia. J Biomed Mater Res 1989;23(1):45-61. (Crossref)

15. Kwiatkowski S, Geller W. A preliminary consideration of the glass ceramic dowel post and core. Int J Prosthodont 1989;2(1):51-55.

16. Blatz MB, Sadan A, Kern M. Resin-ceramic bonding: a review of literature. J Prosthet Dent. 2003;89:268-274. (Crossref)

17. Al-harbi F, Nathanson D. In vitro assessment of retention of four esthetic dowels to resin core foundation and teeth. J Prosthet Dent 2003; 90: 547-555. (Crossref)

18. Balbosh, A., Kern, M. Effect of surface treatment on retention of glass fiber endodontic posts. J Prosthet Dent 2006; 95: 218 223. (Crossref)

19. Cohen BI, Pagnillo MK, Newman I et al. Retention of core material supported by three post head designs. J Prosthet Dent 2000; 83:624-628. (Crossref)

20. Sahafi A, Peutzfeldt A, Asmussen E et al. Effect of surface treatment of prefabricated posts on bonding of resin cement. Oper Dent 2004;1:60-68.

21. Kern $M$, Wegner SM. Bonding to zirconia ceramic: adhesion methods and their durability. Dent Mater. 1998;14:64-71. (Crossref)

22. Derand $P$, Derand $T$. Bond strength of luting cements to zirconium oxide ceramics. Int J Prosthodont. 2000;13(2):131 135.

23. Akgungor $G$, Sen D, Aydın M. Infleunce of different surface treatments on the short-term bond strength and durability between a zirconia post and a composite resin core material. $J$ Prosthet Dent 2008; 99(5): 388-399. (Crossref)

24. Almufleh BS, Aleisa KI, Morgano SM. Effect of surface treatment and type of cement on push-out bond strength of zirconium oxide posts. J Prosthet Dent 2014;112(4):957-963. (Crossref) 